\title{
Yüksek tibial osteotominin kalça ve ayak bileği eklemlerine etkisi
}

\section{The effect of high tibial osteotomy on the hip and the ankle joints}

\author{
Sefa Müezzinoğlu, Levent Umur \\ Acıbadem Kadıköy Hastanesi, Ortopedi ve Travmatoloji Bölümü, İstanbul
}

Yüksek Tibial Osteotomi (YTO), dizin yük dağılımını değiştirmek için alt ekstremitenin yük aksını değiştirirken, ekstremitenin diğer iki eklemini de etkiler. Özellikle bu değişiklikler ayak bileğinde daha çok izlenir ve YTO ile oluşturulan dizilim değişikliği derecesi ile ilişkilidir. Asemptomatik ayak bileğinde YTO sonrası talus tiltinin bozulması semptomların oluşmasında etkili bulunmuştur. YTO öncesi ayak bilek muayenesinin ayrıntılı yapılması önemli görünmektedir.

Anahtar sözcülkler: YTO; ayak bileği; talar tilt; kalça
High Tibial Osteotomy (HTO) affects the other two ipsilateral joints while changing the load axis of the lower limb to alter the knee load distribution. In particular, these changes are more common in the ankle and related to the degree of axis change created by HTO. The impairment of talar tilt was found effective in the occurrence of symptoms in an asymptomatic ankle after HTO. Thorough examination of the ankle before HTO procedure seems essential.

Key words: HTO; ankle; talar tilt; hip
Y üksek Tibial Osteotomi (YTO), erken dönem diz artrozunun tedavisinde giderek daha fazla tartışılmakta ve uygulanmaktadır. ${ }^{[1,2]}$ Bu süreçle birlikte osteotominin endikasyon sınırları, etkileri ve sonuçları üzerinde daha ayrıntılı çalışmalar gündeme gelmiş ve yeni tartışma başlıkları açılmıştır. Bunlardan biri de dizin yük dağılımını değiştirmek için yapılan osteotominin diğer eklemler üzerinde etkisinin ne şekilde olacağıdır. ${ }^{[3]}$

Alt ekstremite dizilimi literatürde ayrıntılı olarak çalışılmış ve varsayılan doğal dizilim şekli belli sınırlar içindeki derecelerde kabul edilmiştir. ${ }^{[4]}$ Ancak dizilim değişikliklerinin klinik sonuçları ve doğal seyri konusunda tartışmalar devam etmektedir. Bunun nedeni de sonuçların büyük ölçüde kişisel faktörlerden etkilenmesidir. Çeşitli nedenlerle yapılan alt ekstremite osteotomilerinin uzun dönem etkileri ise daha çok hedef eklem düzeyinde tartışılmıştır. ${ }^{[5]}$ YTO gibi alt ekstremitede belirgin dizilim değişikliği yapan bir işlemin sadece hedeflediği eklemi değil, bu bütünleşik yapının diğer iskelet yapılarını da etkilemesi kaçınılmazdır. Bu etkinin kısa ve uzun dönem etkileri gözden kaçmamış, ancak bu konuda ayrıntılı çalışmalar yakın zamana kadar yeterince yapılmamıştır.
Ekstremitenin fonksiyonunun temelde hareket olması nedeniyle, yük dağılımı, statik değil dinamik bir süreç içinde oluşur. Üç boyutlu olarak oluşan hareketler ile eklemlerde yük alanında ve niceliğinde sürekli değişiklikler meydana gelir. Salınım fazında ayak daha merkeze, kalça adduksiyona, tibia adduksiyona gider. Diz ve ayak bileğinde mediolateral yönde makaslama kuvvetleri oluşur. iliotibial bant ve kalçada abduksiyon gerilme kuvvetleri ile yükün medialde kalması sağlanır. Koronal planda oluşan salınımlar diz seviyesinde karşılandığı gibi, yer ile temasta büyük ölçüde subtalar eklem ile tolere edilir. ${ }^{[4,6]}$ Dizilimde oluşan herhangi bir değişiklik bu yüklerde ve aktarımlarında değişiklikler meydana getirerek her üç eklemi de değişik derecelerde etkiler. ${ }^{[7]}$

Her ne kadar alt ekstremite dizilim değişikliğinin kalça üzerine etkisi olacağı beklense de bu konuda çalışma çok sınırlıdır. Kalçanın pozisyonu dizilim referans noktalarını değiştirebildiği gibi, kalça hareketlerinde değişiklik yapan durumlar, dizin yük dağılımını etkiler. Femoro-asetabular sıkışmaya bağlı iç rotasyon kısıtlılığında, kalça eksternal rotasyonda yürürken duruş fazında diz medialine binen yük artar. Ayağın pronasyon veya supinasyonda olması da dizilimin referans

- İletişim adresi: Prof. Dr. Ü. Sefa Müezzinoğlu, Acıbadem Kadıköy Hastanesi Ortopedi ve Travmatoloji Bölümü, Tekin Sk. No 8, Kadıköy, İstanbul Tel: 0532 - 3564506 e-posta: sefa.muezzinoglu@acibadem.com.tr

- Geliș tarihi: 4 Mart $2020 \quad$ Kabul tarihi: 24 Mart 2020 


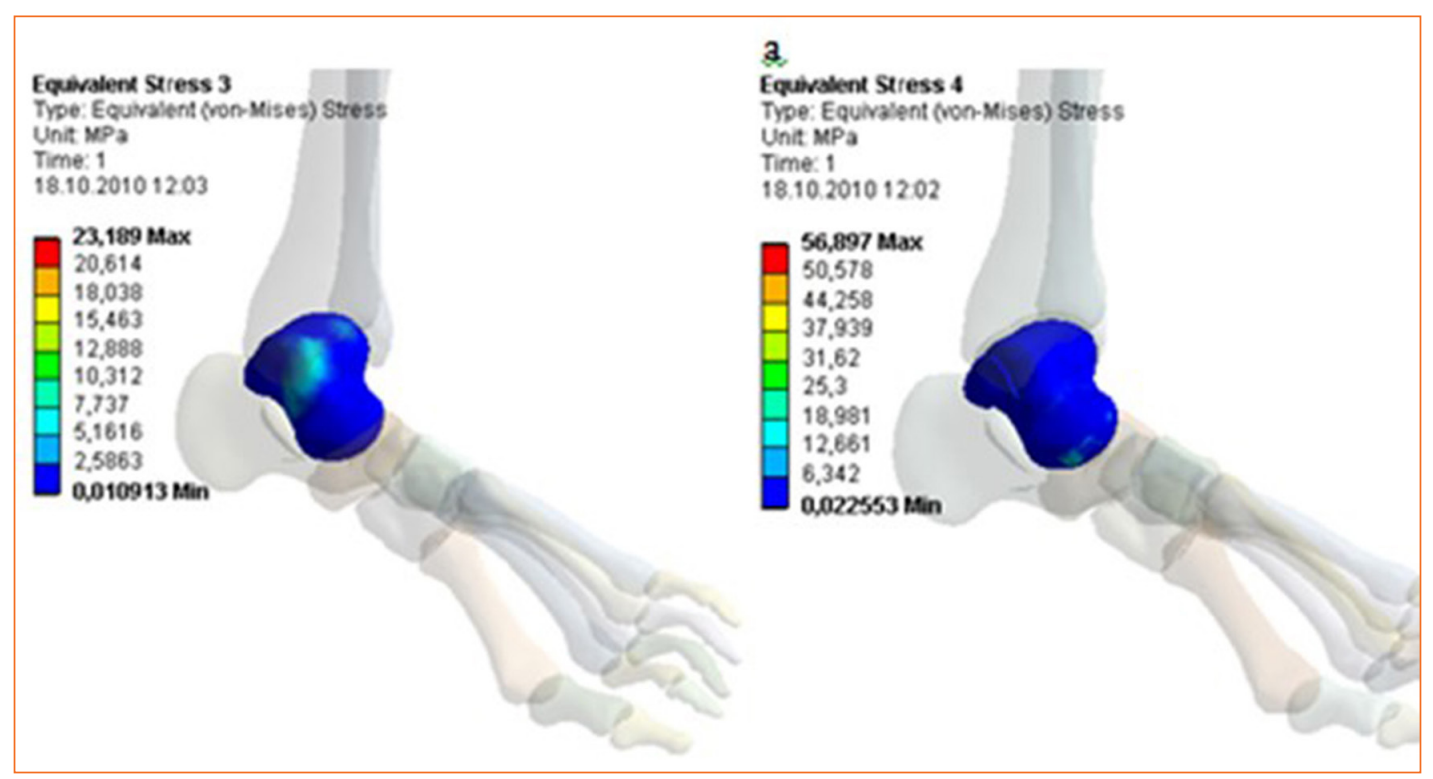

Şekil 1. a, b. YTO öncesi (a) ve sonrasında (b) yük dağılımındaki değişikliği gösteren sonlu eleman çalışması modellemesi. ${ }^{[11]}$

noktasını ve yük dağııımını değiştirir. Moghtadaei ve ark., büyük trokanter pozisyonuna bakarak abduktor momenti ile yorum yaparak, YTO öncesi ve sonrası yapılan ölçümlerle abduktor momentinin değiştiğini göstermişlerdir. ${ }^{[8]}$ Ancak diz osteotomisi sonrası kalçada oluşabilecek değiş̧ikliklerin kısa ve uzun dönem etkileri konusunda yeterince bilgi yoktur ve araştırmaya açıktır.

YTO'nun ayak bileği üzerine klinik sonuçları ise daha geniş çalışılmış ve bu başlıkta deneysel çalışmalar yapılmıştır. Aynı grup tarafından yapılan iki çalışmada, proksimal tibianın valgusundaki orta ve ileri derecedeki değişikliklerin tibio-talar bası noktalarında belirgin değişiklik yarattığını, bası alanını azalttığını, birim alana düşen yükü artırdığını ve rotasyonel değişikliklerin de yük dağılımını değiştirdiğini göstermişlerdir. ${ }^{[9,10]}$ Özkan ve ark., konuyu sonlu eleman tekniğini uygulayarak üç boyutlu katı modelleme ile araştırdıkları çalışmada benzer sonuçlara ulaşmışlardır. Bilgisayarlı tomografi ile elde edilen üç boyutlu modellere uygulanan YTO işleminin öncesinde ve sonrasında ayak kemikleri üzerine binen yükler bilgisayar ortamındaki modelleme ile çalışılarak yapılan deneysel çalışma sonucunda ayak ve ayak bilek kemikleri üzerinde gerilim kuvvetlerinin azalarak tibiaya aktarıldığı gösterilmiştir (Şekil 1). ${ }^{[11]}$

Bu çalışmalar ışığında nötral/valgus ayak bileğinde uygun açı ile yapılan YTO sonrası talar tiltin nötralleşmesi görülürken, aşırı düzeltme sonrası ayak bileğinde varus deformitesi oluşması görülür (Şekil 2).
Bu doğrultuda operasyon öncesi gözden kaçan ayak bileğinde varus deformitesi olan bir hastaya uygulanan YTO prosedürü, ayak bileğindeki deformiteyi artırarak, semptomların artmasına veya asemptomatik hastayı semptomatik hale getirmeye neden olacağı gözönünde bulundurulmalıdır (Şekil 3).

Klinik değerlendirmelere bakıldığında, Takeuchi ve ark. aynı ekstremitede hem dizin hem de ayak bileğinin semptomatik olduğu, 10 hastanın 16 dizinin YTO sonrası radyolojik ve klinik sonuçlarını değerlendirmişlerdir. Bu çalışmada YTO öncesi $6^{\circ}$ varus olan ortalama diz açısı, ortalama $12^{\circ}$ valgusa gelmiş ve ortalama Hospital for Special Surgery (HSS) diz skorunun 54'den 91 puana yükseldiği görülmüştür. Dize yapılan osteotomi sonrası, talusun horizontal eksen ile yaptığı açı olan talus tilt açısı $18^{\circ}$ 'den $6^{\circ}$ ye gerilemiştir. Klinik olarak da daha önce semptomatik olan bu ayak bileklerinde AOFAS (American Orthopaedic Foot and Ankle Society) skoru da 54'den 86'ya yükselmiştir. Alt ekstremite diziliminin düzelmesinin ayak bileğinin açısal düzelmesine ve dolayısıyla semptomunun azalmasına etkisi olduğunu göstermişlerdir. ${ }^{[12]}$ Ayak bileği daha önce asemptomatik olan hastaların açık kama YTO sonrası araştırıldığı Shah ve ark.'nın çalışmasında, değerlendirilen 35 hastanın yedisinde alt ekstremite diziliminin valgusa alınması sonrasında ayak bileği semptomları gelişmiştir. Bu çalışmanın dikkat çeken yanı, talus inklinasyon açısının fazla arttı̆̆ grupta semptomların daha fazla artmış olmasıdır; $10^{\circ}$ altındaki 19 hastanın 

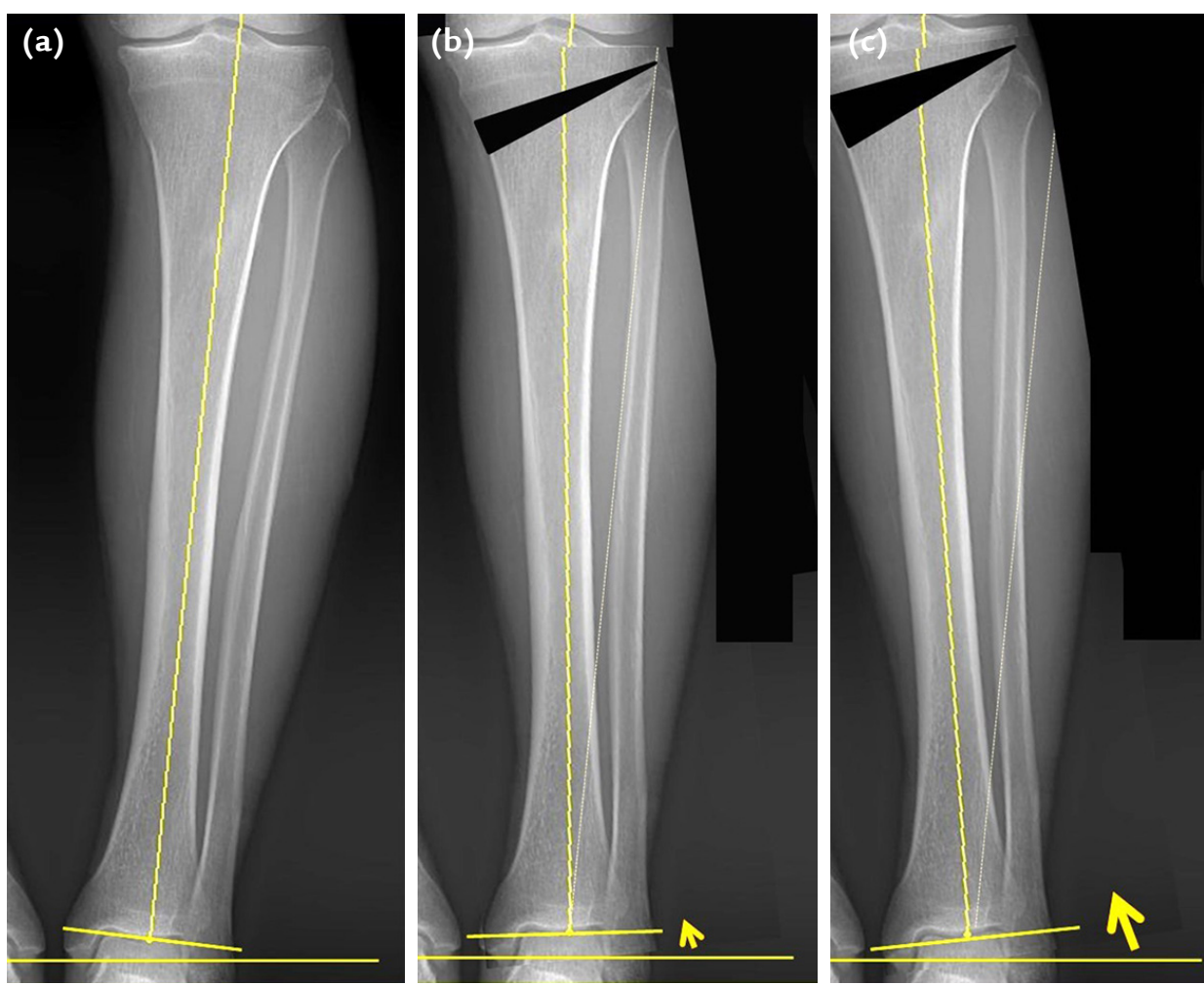

Şekil 2. a-c. Nötral/valgus talar tilt açısı olan hastada (a) YTO sonrası valgus açılanmasının düzelmesi (b) ve aşırı düzeltme sonrası varus deformitesi oluşumunun (c) şematik gösterimi.
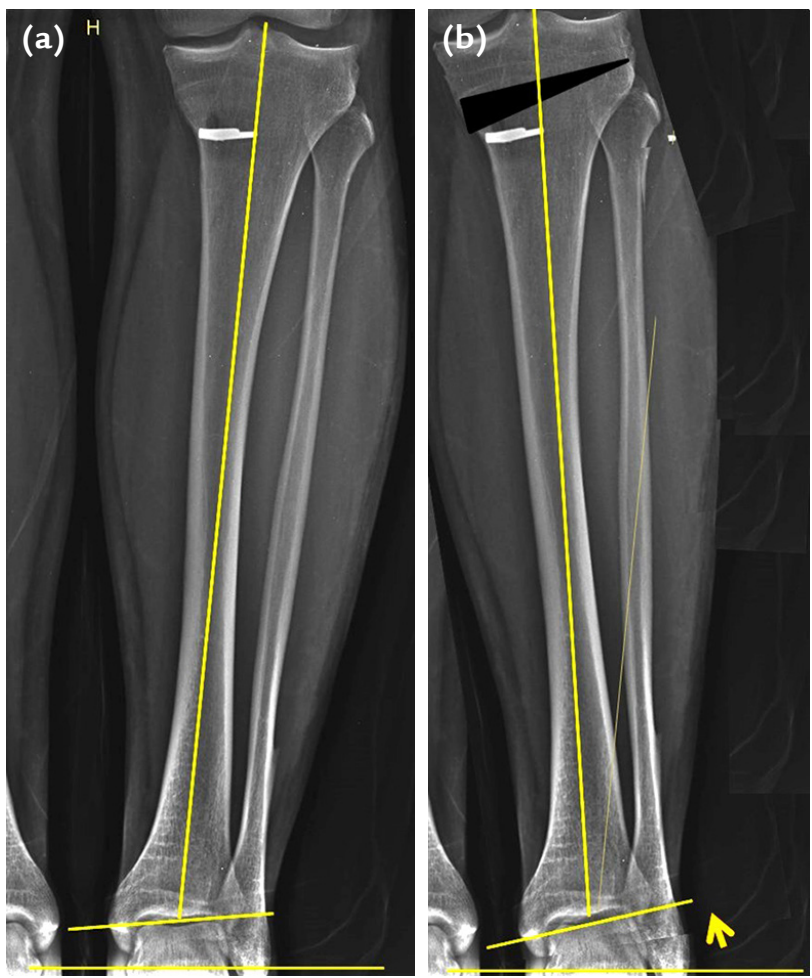

Şekil 3. a, b. Ayak bileği varus deformitesi olan hastada (a), YTO sonrası varus deformitesindeki artışının (b) şematik gösterimi. birinde, $10^{\circ}$ üstündeki 16 hastanın altısında semptom oluşmuştur. ${ }^{[13]}$ Buna karşılık Jeong ve ark. tarafindan sunulan tek olguda, daha önce asemptomatik olan ayak bileği, YTO sonrası ağrılı hale gelmiştir. Bu olgu değerlendirildiğinde, asemptomatik olan ayak bileğinde talus tilt açısının da ameliyat öncesi düzgün olduğu, ameliyat sonrası ileri derecede bozulmuş olduğu izlenmektedir. Daha sonra yapılan supramalleolar osteotomi ile bu tilt düzeltilmiş ve ayak bileğinin semptomları azalmıştır. ${ }^{[14]} \mathrm{Bu}$ çalışmalar talusun horizontal eksen ile ilişkisinin YTO sonrası ayak bileği semptomlarında rolünün olduğunu göstermektedir. Choi ve ark.'nın bu ilişkiyi araştırdıkları çalışmada hastalar, ameliyat sonrası ayak bileğinin yere paralel olma derecesine göre iki gruba ayrılmıştır. YTO sonrası ayak bileğinin yere daha az paralel olduğu ikinci grupta semptomların daha fazla olduğu gösterilmiştir. Bu durum, diz seviyesinde yapılan osteotomi ile ayak bileğinde oluşan değişikliklerin büyük kısmının subtalar eklemden kompanse edildiği, subtalar hareket kısıtlılığında, ayak bileğinin tekrar uyum sağlayamaması ve ayak bileğinde yük dağııııının değişmesi ile açıklanmıştır. ${ }^{[15]}$ Alt ekstremite diziliminindeki değişikliklerin ayak bileğinde semptomatik sonuçlara yol açmaması için, subtalar eklemin hareketliliğinin önemi vurgulanmıştır. Ayak bileği hareketliliği yeterli olsa da, $14^{\circ}$ üzerindeki düzeltmelerin 
yeterince kompanse edilemediği ve koronal dizilimde bozulmaya neden olduğu Ariyawatkul ve ark. tarafından gösterilmiştir. ${ }^{[16]}$ Diz seviyesindeki osteotominin ayak bileği üzerinde etkisi olacağı değerlendirilerek planlanan Elson ve ark. sunduğu olguda endikasyon genişletilerek, osteoartritik ayak bileğinin dizilimini düzeltmede YTO'nun pozitif etkisi gösterilmiştir. ${ }^{[17]}$

Sonuç olarak alt ekstremite dizilimi bütün eklemler tarafından oluşturulan dinamik bir süreçtir. YTO cerrahisi ile diz seviyesinde yapılan valgus değişikliğinin, alt ekstremitenin her iki ucundaki eklemlerinde değişiklik yapması kaçınılmazdır. Proksimalde kalça eklemindeki değişiklikler daha çok abduktor momentinin değişikliği düzeyinde çalışılmış, ancak eklem semptomları ve ekleme uzun dönem etkileri açısından çalışılmalar henüz yetersizdir. Ayak bileğinde ise hem semptomatik, hem de asemptomatik ayak bilekleri üzerindeki etkileri çalışılmıştır. Diz seviyesinde yapılan osteotomi sonrası, ayak bileğinin horizontal eksen ile ilişkisinde oluşturulan değişikliğin ayak bileğinde gelişen semptomlardaki önemi gösterilmiştir. Talar tiltde artan derecelerdeki değişikliklerde, ayak bileğinde semptomların daha fazla olduğu gösterilmiştir. Subtalar eklemin oluşturduğu kompansasyonun, bu etkiyi belli derecelere kadar tolere edebildiği, ancak ileri derecelerde tolere edilemediği yorumu yapılmıştır.

Bu nedenle YTO işlemi planlanan hastaların ameliyat öncesi hazırlığında ayak bileğinin de ayrıntılı değerlendirilmesinin önemi ortaya çıkmaktadır. Ayak bilek patolojileri ayrıntılı incelenmeli, subtalar hareketin yeterliliği araştırılmalıdır. Ayak bileği, subtalar patoloji ve semptomları olan hastalarda, diz seviyesindeki düzeltme osteotomi kararları ve açı değişim miktarları yeniden değerlendirilmelidir. İleri derecelerdeki açı düzeltmelerinde asemptomatik ayak bileklerinde semptomların oluşabileceği bilinmelidir.

\section{KAYNAKLAR}

1. Koshino T, Yoshida T, Ara Y, Saito I, Saito T. Fifteen to twentyeight year's follow-up results of high tibial valgus osteotomy for osteoarthritic knee. Knee 2004;11(6):439-44. Crossref

2. Sabzevari S, Ebrahimpour A, Roudi MK, Kachooei AR. High Tibial Osteotomy: A Systematic Review and Current Concept. Arch Bone Jt Surg 2016;4(3):204-12. https://www.ncbi.nlm. nih.gov/pmc/articles/PMC4969364/
3. McKellop HA, Llinas A, Sarmiento A. Effects of tibial malalignment on the knee and ankle. Orthop Clin North Am 1994;25(3):415-23.

4. Hsu RWW, Himeno S, Coventry MB, Chao EYS. Normal axial alignment of the lower extremity and load-bearing distribution at the knee. Clin Orthop Relat Res 1990;(255):215-27. Crossref

5. Amis AA. Biomechanics of high tibial osteotomy. Knee Surg Sports Traumatol Arthrosc 2013;21(1):197-205. Crossref

6. Flandry F, Hommel G. Normal anatomy and biomechanics of the knee. Sports Med Arthrosc Rev 2011;19(2):82-92. Crossref

7. Weidenhielm L, Svensson OK, Broström LA, Rudberg U. Change in adduction moment about the knee after high tibial osteotomy and prosthetic replacement in osteoarthrosis of the knee. Clin Biomech (Bristol, Avon) 1992;7(2):91-6. Crossref

8. Moghtadaei M, Yeganeh A, Boddouhi B, Alaee A, Farahini $H$, Otoukesh B. Effect of high tibial osteotomy on hip biomechanics in patients with genu varum: A prospective cohort study. Interv Med Appl Sci 2017;9(2):94-9. Crossref

9. Suero EM, Sabbagh Y, Westphal R, Hawi N, Citak M, Wahl FM, Krettek C, Liodakis E. Effect of medial opening wedge high tibial osteotomy on intraarticular knee and ankle contact pressures. J Orthop Res 2015;33(4):598-604. Crossref

10. Suero EM, Hawi N, Westphal R, Sabbagh Y, Citak M, Wahl FM, Krettek C, Liodakis E. The effect of distal tibial rotation during high tibial osteotomy on the contact pressures in the knee and ankle joints. Knee Surg Sports Traumatol Arthrosc 2017;25(1):299-305. Crossref

11. Ozkan A, Atmaca H, Mutlu I, Celik T, Uğur L, Kişioğlu Y. Stress distribution comparisons of foot bones in patient with tibia vara: a finite element study. Acta Bioeng Biomech 2013;15(4):67-72.

12. Takeuchi R, Saito $T$, Koshino $T$. Clinical results of a valgus high tibial osteotomy for the treatment of osteoarthritis of the knee and the ipsilateral ankle. Knee 2008;15(3):196-200. Crossref

13. Shah SM, Roberts J, Picard F. Ankle and Hindfoot Symptoms after Medial Open Wedge High Tibial Osteotomy. J Knee Surg 2019;32(3):269-73. Crossref

14. Jeong BO, SooHoo NF. Ankle Deformity After High Tibial Osteotomy for Correction of Varus Knee: A Case Report. Foot Ankle Int 2014;35(7):725-9. Crossref

15. Choi GW, Yang JH, Park JH, Yun HH, Lee YI, Chae JE, Yoon JR. Changes in coronal alignment of the ankle joint after high tibial osteotomy. Knee Surg Sports Traumatol Arthrosc 2017;25(3):838-45. Crossref

16. Ariyawatkul T, Pornrattanamaneewong C, Narkbunnam $\mathrm{R}$, Chareancholvanich K. Talar coronal malalignment as a consequence after high tibial osteotomy in osteoarthritic knee patients. J Med Assoc Thai 2014;97 Suppl 9:S34-8.

17. Elson DW, Paweleck JE, Shields DW, Dawson MJ, Ferrier GM. Stretching the indications: high tibial osteotomy used successfully to treat isolated ankle symptoms. BMJ Case Rep 2013;2013:bcr2013200527. Crossref 